$$
\begin{array}{cl}
P & \text { GA-A22205 } \\
\text { FFR } 01 \text { CONF-9509238--10 } & \\
\text { OSTI } & \\
\text { JET/DIII-D SIZE SCALING } & \\
\text { OF THE H-MODE POWER THRESHOLD }
\end{array}
$$

by

T.N. CARLSTROM, D.J. CAMPBELL, J.G. CORDEY, J.C. DeBOO, R.J. GROEBNER, E. RIGHI, G. SAILBENE, D.P. SCHISSEL, D. START, and K. THOMSEN 


\section{DISCLAIMER}

This report was prepared as an account of work sponsored by an agency of the United States Government. Neither the United States Government nor any agency thereof, nor any of their employees, makes any warranty, express or implied, or assumes any legal liability or responsibility for the accuracy, completeness, or usefulness of any information, apparatus, product, or process disclosed, or represents that its use would not infringe privately owned rights. Reference herein to any specific commercial product, process, or service by trade name, trademark, manufacturer, or otherwise, does not necessarily constitute or imply its endorsement, recommendation, or favoring by the United States Government or any agency thereof. The views and opinions of authors expressed herein do not necessarily state or reflect those of the United States Government or any agency thereof.

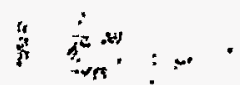




\title{
JET/DIII-D SIZE SCALING OF THE H-MODE POWER THRESHOLD
}

\author{
by \\ T.N. CARLSTROM, D.J. CAMPBELL, ${ }^{*}$ J.G. CORDEY, ${ }^{*}$ \\ J.C. DeBOO, R.J. GROEBNER, E. RIGHI, ${ }^{*}$ G. SAILBENE, ${ }^{*}$ \\ D.P. SCHISSEL, D. START, ${ }^{*}$ and K. THOMSEN*
}

This is a preprint of an invited paper presented at the International Atomic Energy Agency Meeting on H-Mode Physics, September 18-20, 1995, in Princeton, New Jersey, and to be published in the PROCEEDINGS.

\author{
Work supported by \\ the U.S. Department of Energy \\ under Contract No. DE-AC03-89ER51114
}

*Joint European Torus, Abingdon, United Kingdom.

GA PROJECT 3466 OCTOBER 1995 


\title{
JET/DIII-D size scaling of the $\mathrm{H}$-mode power threshold
}

\author{
T.N.Caristrom, ${ }^{a}$ D.J.Campbell, ${ }^{b}$ J.G.Cordey, b J.C.DeBoo, ${ }^{a}$ R.J.Groebner, ${ }^{a}$ \\ E.Righi, ${ }^{b}$ G.Saibene, ${ }^{b}$ D.P.Schissel, ${ }^{a}$ D.Start, ${ }^{b}$ and K.Thomsen ${ }^{b}$ \\ a'General Atomics, P.O. Box 85608, San Diego, USA \\ bJoint European Torus, Abingdon, United Kingdom
}

\begin{abstract}
Previous scaling results indicate that the $\mathrm{H}$-mode power threshold increases nearly linearly with the line averaged density, $\vec{n}_{e}$, and the toriodal field, $\mathrm{B}_{\mathrm{t}}$. The power threshold was measured in similar, ITER-like, discharges in JET and DIII-D, at the same $\bar{n}_{e}$ and $\mathrm{B}_{\mathrm{t}}$ in order to determine the size scaling of the power threshold. The results indicate a size scaling proportional to the surface area, $S^{0.5}$, which is weaker than the linear surface area dependence previously assumed.
\end{abstract}

\section{Introduction}

A critical need for ITER is the determination of the power requirement to achieve the enhanced confinement regime of $\mathrm{H}$-mode. Existing devices can operate at many of the parameters of ITER such as $\mathrm{B}_{\mathrm{t}}, \bar{n}_{e}, q$ and $\beta$. However, the physical dimensions of ITER are much larger than present devices. Size scaling then becomes one of the most significant unknowns when extrapolating threshold power requirements to ITER. Since the $\mathrm{H}$-mode transition occurs at the plasma edge, it is believed that the power flow through the surface is the important quantity. It has been found that if the power threshold for various machines is normalized to the plasma surface area and plotted against $\bar{n}_{e} \mathrm{~B}_{\mathrm{t}}$, some ordering of the data is realized.[1] However, there are still variations of 2-5 between normalized power thresholds for different machines and the $\bar{n}_{e} \mathrm{~B}_{\mathrm{t}}$ scaling in individual machines is not always apparent. Numerous other effects such as wall conditioning, plasma-wall distances, neutral pressure, and impurity levels can also influence the power threshold. With such a large number of variables affecting the power threshold, it becomes difficult to identify the size scaling from a database containing many machines and many conditions.'

Recently, the power threshold scaling with $\bar{n}_{e}$ and $\mathrm{B}_{\mathrm{t}}$ was measured in JET $[2,3]$ and found to be very similar to that observed in DII-D [4], namely a linear dependence on $\mathrm{B}_{\mathrm{t}}$ and a roughly linear dependence on $\bar{n}_{e}$. This similar behavior of the power threshold scaling enables us to compare two identically shaped "ITER-like" discharges at $q 95=3.0$ in JET and DIII-D, at the same $\bar{n}_{e}$ $\left(3 \times 10^{19} \mathrm{~m}^{-3}\right)$ and $\mathrm{B}_{\mathrm{t}}(2.0 \mathrm{~T})$, and determine the size scaling of the power threshold. The surface area for the DIII-D discharge is $45 \mathrm{~m}^{2}$ and for JET it is $145 \mathrm{~m}^{2}$, giving a factor of 3 range in the relevant size. The surface area for ITER is $1250 \mathrm{~m}^{2}$, so predicting the power threshold for ITER will require an extrapolation of a factor of 9 above JET. The purpose of this paper is to compare the power threshold in two different sized machines, JET and DIII-D, by holding all the other parameters known to influence the power threshold as constant as possible. Any difference in the power threshold can then be attributed to the difference in size.

\section{Results}

By taking advantage of the flexible shaping capabilities of DIII-D, we were able to closely match the JET discharge. A comparison of the plasma shapes is shown in Figure 1. Table I lists the important parameters for ITER, JET, and DIII-D. The match between DIII-D and JET was excellent for $\mathrm{q} 95, \mathrm{~B}_{t}$, and $K$. The average line density, $\bar{n}_{e}$, was about $10 \%$ higher in the DIII-D 

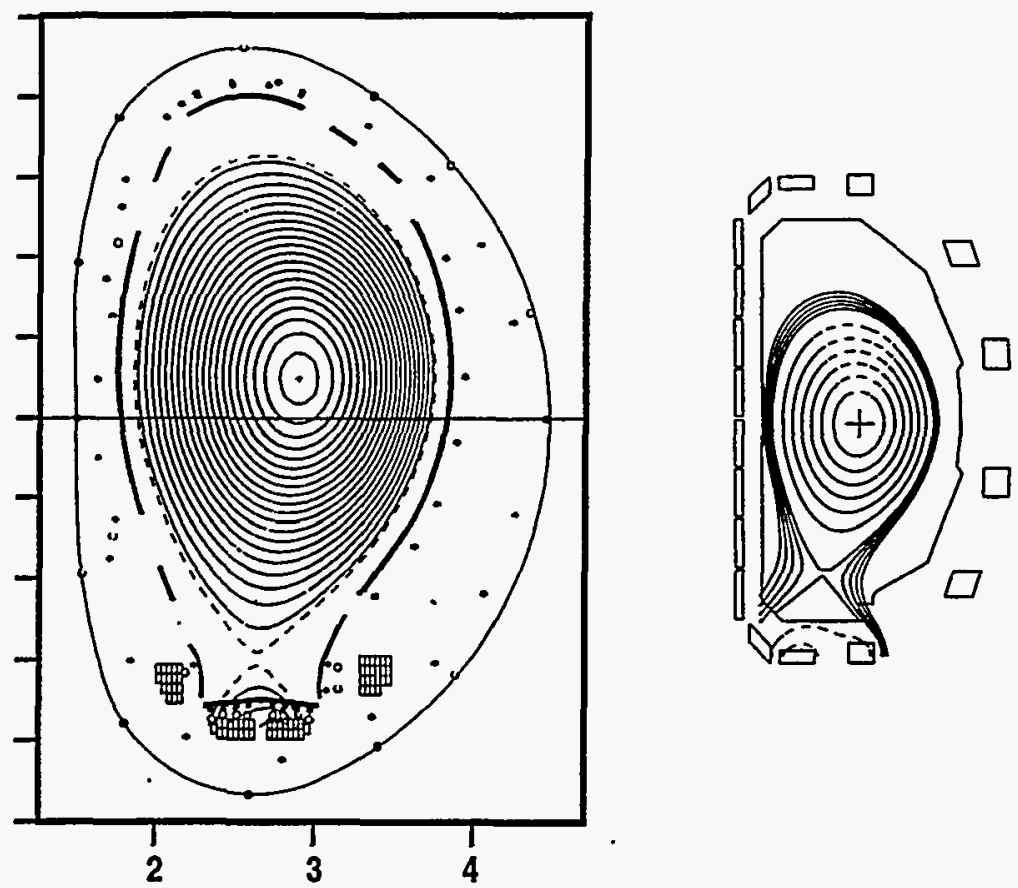

Figure 1. Equilibrium flux plots for ITER-like discharges in JET and DIII-D.

Table I. Plasma parameter comparison of DIII-D, JET, and ITER

\begin{tabular}{lllll}
\hline Parameter & ITER & JET & DIII-D & DIII-D (Ref) \\
\hline Shot/design & 1995 & 33439 & 86276 & 86280 \\
Unmatched Parameters & & & & \\
$\quad$ a (m) & 2.80 & 0.95 & 0.55 & 0.63 \\
R (m) & 8.14 & 2.86 & 1.63 & 1.68 \\
I $_{\mathrm{p}}(\mathrm{MA})$ & 21.0 & 2.00 & 1.25 & 1.35 \\
S (m $\left.{ }^{2}\right)$ & 1282.4 & 145.0 & 48.3 & 61.7 \\
Parameters matched between DII-D and JET & & \\
q95 & 3.00 & 3.09 & 3.00 & 4.60 \\
B $(\mathrm{T})$ & 5.68 & 2.12 & 2.00 & 2.06 \\
K & 1.75 & 1.63 & 1.64 & 1.85 \\
n (x 1019 m-3) & 5.0 & 3.0 & 3.3 & 2.16 \\
Plasma wall distances & & & & \\
Gapin (m) & & 0.109 & 0.067 & 0.033 \\
Gapout (m) & & 0.091 & 0.187 & 0.061 \\
Gaptop (m) & & 0.408 & 0.610 & 0.212 \\
X-point (m) & & 0.258 & 0.301 & 0.177 \\
\hline
\end{tabular}

discharge. The plasma-wall distances could not be matched and still maintain the ITER shape. However, we attempted to keep the X-point distance as close to the same as possible in order to minimize differences in the divertor geometry. The column labeled DIII-D (Ref) contains information for a reference shot used to connect these threshold results to previous scans of the power threshold, $\mathrm{P}_{\mathrm{th}}$, on DIII-D [4], in which the $\bar{n}_{e}$ and $\mathrm{B}_{\mathrm{t}}$ scalings were determined. Although it was intended to produce a reference discharge at the same density, a lower density was obtained 
because of a misadjustment in the density feedback control. However, $\mathrm{P}_{\text {th }}$ measured for this shot is consistent with previous results indicating the machine conditions have not changed significantly.

The power threshold results are presented in Figures 2 and 3 for density scans in JET and DIII-D respectively. Because of limited experimental time, the DIII-D density scan only covers the mid-range of the JET scan. We have defined the power threshold, $\mathrm{P}_{\text {net }}$, to be the power that flows through the edge of the plasma

$$
\mathrm{P}_{\text {net }}=\mathrm{P}_{\text {tot }}-d \mathrm{~W}_{\mathrm{p}} / \mathrm{dt}-\mathrm{P}_{\mathrm{rad}} \text { (core), }
$$

where $P_{\text {tot }}=P_{\Omega}+P_{a b s}, P_{\Omega}$ is the ohmic input power, $\mathrm{P}_{\mathrm{abs}}$ is the absorbed neutral beam injected power after accounting for shine through and fast ion losses, (both effects are small, accounting for less than a $10 \%$ correction), $\mathrm{W}_{\mathrm{p}}$ is the plasma stored energy, and $\mathrm{P}_{\mathrm{rad}}$ (core) is the radiated power within the separatrix. Estimates for the measurement error of these quantities are $10-20 \%$ for $P_{\Omega}, \mathrm{dW}_{\mathrm{p}} / \mathrm{dt}$,

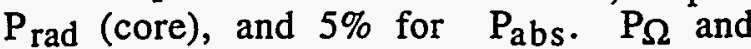
$\mathrm{P}_{\mathrm{rad}}$ (core) are similar in both JET and DIII-D, indicating a lack of size scaling of these parameters.

Figure 4 shows $P_{\text {tot }}$ and $P_{\text {net }}$ normalized by $\bar{n}_{e} \mathrm{~B}_{\mathrm{t}}$, versus surface area, $\mathrm{S}$. Data from DIII-D reference discharges, not in the ITER shape, are also shown at $\mathrm{S}=61 \mathrm{~m}^{2}$. Although

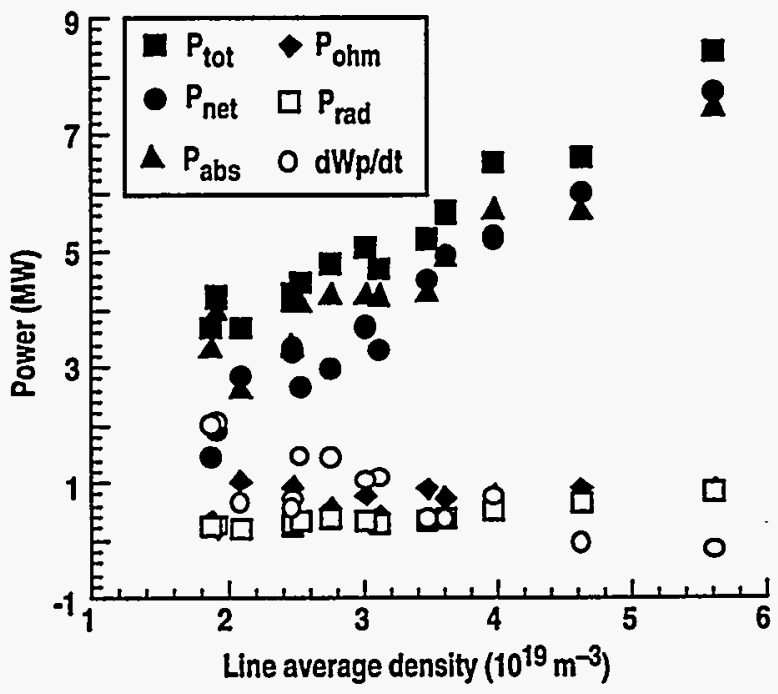

Figure 2. Various power evaluated just before the $\mathrm{L}-\mathrm{H}$ transition for ITER-like discharges in JET. Discharge parameters were: $\mathrm{B}_{\mathrm{t}}=2.1 \mathrm{~T}, \mathrm{I}_{\mathrm{p}}=$ $2.0 \mathrm{MA}, \mathrm{q}_{95}=3.0$, neutral beam heated.

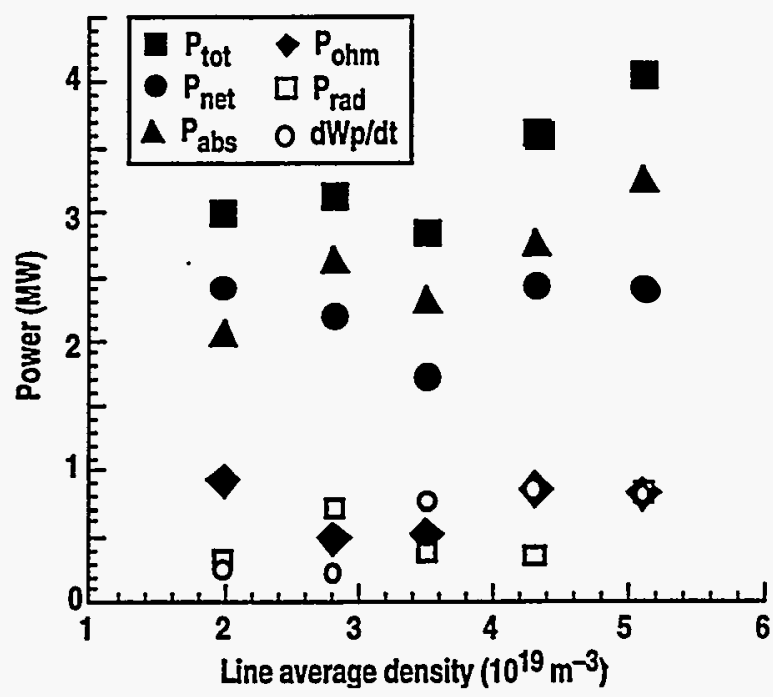

Figure 3. Various power evaluated just before the L-H transition for ITER-like discharges in DIII-D. Discharge parameters were: $\mathrm{B}_{\mathrm{t}}=2.0 \mathrm{~T}, \mathrm{I}_{\mathrm{p}}=$ $1.25 \mathrm{MA}$, q95 $=3.0$, neutral beam heated.

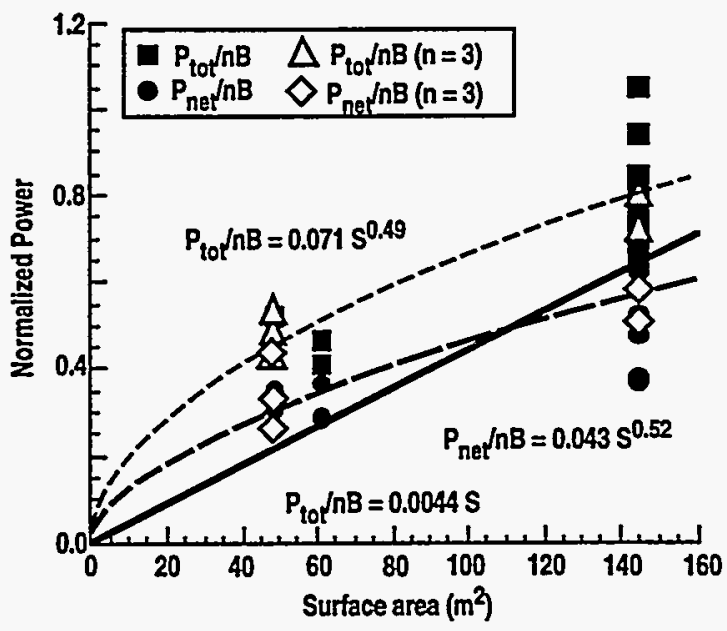

Figure 4. $\mathrm{P}_{\text {tot }}$ and $\mathrm{P}_{\text {net }}$ normalized by $\bar{n}_{e} \mathrm{~B}_{\mathrm{t}}$ versus the plasma surface area for ITER-like discharges in DIII-D and JET. All discharges have $B_{t}=2 T$ and q95 $=3$. The discharges at $\bar{n}_{e}=3$ are shown with open symbols. The dashed curves are power law fits to the data for all densities.

$P_{\text {tot }}$ is lower for this discharge than the DIII-D ITER-shape discharge at $\mathrm{S}=48 \mathrm{~m}^{2}, \mathrm{P}_{\mathrm{rad}}$ (core) was also lower so that $P_{n e t}$ was about the same for the two discharges. The JET threshold is slightly higher than a prediction based on $\mathrm{P}_{\text {tot }}=$ $0.0044 \bar{n}_{e} \mathrm{~B}_{\mathrm{t}} \mathrm{S}$ [1] (solid curve in Figure 4), whereas the DIII-D result is about twice the prediction. Taken at face value, this indicates that the surface area is not the correct parameter for the size scaling. Assuming a power law 
form for the size scaling, these results indicate that $S^{0.5}$ is a better scaling factor as shown by the dashed curves in Figure 4. Both $\mathrm{P}_{\text {tot }}$ and $\mathrm{P}_{\text {net }}$ show this same behavior.

The reference discharge is consistent with our previous work but the ITER-like DIII-D discharge was developmental and there may have been some systematic problems which produced higher power thresholds. Neutral pressure is one area where we have started to investigate. Shown in Table $I$ is the neutral pressure measured near the midplane, $\mathrm{P}_{0}$ (mid), and the pressure measured in the private flux region of the divertor, $\mathrm{P}_{0}$ (div). First, there is a significant difference between the pressures in JET and DIII-D. There is some uncertainty in the absolute calibration of the instruments however, and this is an area for future work. Comparing just the two DIII-D discharges, where the absolute calibration can be ignored, we find that the ITER-like discharge has a substantially higher divertor pressure. The ratio of $\mathrm{P}_{0}$ (div)/ $\mathrm{P}_{0}$ (mid) is almost nine times higher in the ITER-like discharge, indicating the divertor is more effective in confining neutrals in this configuration. This may be due, in part, to the high $\mathrm{X}$-point and the close proximity of the outer strike point to the divertor baffle in the ITER-like shape. It may also be due to the higher density in the ITER-like discharge and the non-linear dependence of the divertor characteristics on the core plasma density. The radiated power for this dicharge is also considerably higher than the reference discharge. These obsevations suggest that the role of neutrals is different in the two cases. Exactly how this may effect the power threshold is also an area for future study.

\section{Conclusions}

The H-mode power threshold of similar, ITER-like, discharges in JET and DIII-D, were compared at the same $\bar{n}_{e}$ and $\mathrm{B}_{\mathrm{t}}$ in order to determine the size scaling of the power threshold. The results indicate a size scaling proportional to $S^{0.5}$, which is weaker than the linear surface area dependence previously assumed. This is a favorable result for ITER since it reduces the threshold power given by $\mathrm{P}_{\text {tot }}=0.0044 \bar{n}_{\mathrm{e}} \mathrm{B}_{\mathrm{t}} \mathrm{S}$ of $158 \mathrm{MW}$ to $66 \mathrm{MW}$ when predicted by the present scaling of $\mathrm{P}_{\mathrm{tot}}=$ $0.071 \bar{n}_{e} \mathrm{~B}_{t} \mathrm{~S}^{0.49}$,(based on $\bar{n}_{e}=5 \times 10^{19} \mathrm{~m}^{-3}$ ). The neutral pressure is quite different in the two cases and it may play an important role in the determination of the power threshold. Further work in this area is required before meaningful intermachine comparisons can be made.

\section{Acknowledgment}

This is a report of work supported by the U.S. Department of Energy under Contract No. DE-AC0389ER51114 and by Euratom.

\section{References}

[1] ITER H-mode Database Working Group 1994, in Proc. 21st Euro. Conf. on Controlled Fusion and Plasma Physics, vol 1, p. 334

[2] Righi E et al. 1995 in Proc. 22nd Euro. Conf. on Controlled Fusion and Plasma Physics, to be published

[3] Cordey J G et al. 1995, Plasma Phys. Control. Fusion, this conference

[4] Carlstrom T N et al. 1994 Plasma Phys. Control. Fusion 36 A147

Table II. Neutral Pressures ( $10^{-6} \mathrm{mBar}$ )

\begin{tabular}{llll}
\hline Parameter & JET & DIII-D & DIII-D (Ref) \\
\hline Shot & 33439 & 86276 & 86280 \\
$\mathrm{P}_{0}$ (mid) & 0.6 & 9.6 & 8.8 \\
$\mathrm{P}_{0}$ (div) & 243 & 1050 & 111 \\
$\mathrm{P}_{0}$ (div) $/ \mathrm{P}_{0}$ (mid) & 405 & 109 & 12.6 \\
\hline
\end{tabular}




\section{\% general atomics}

P. O. BOX 85608 SAN DIEGO, CA 92186-9784 (619) 455-3000 